\title{
Nutrition-based health in animal production
}

\author{
Clifford A. Adams \\ Kemin AgriFoods Europe, Industriezone Wolfstee, Toekomstlaan 42, 2200 Herentals, Belgium
}

\begin{abstract}
Events such as BSE, foot and mouth disease and avian influenza illustrate the importance of animal health on a global basis. The only practical solution to deal with such problems has usually been mass culling of millions of animals at great effort and expense. Serious consideration needs to be given to nutrition as a practical solution for health maintenance and disease avoidance of animals raised for food. Health or disease derives from a triad of interacting factors; diet-disease agent, diet-host and disease agent-host. Various nutrients and other bioactive feed ingredients, nutricines, directly influence health by inhibiting growth of pathogens or by modulating pathogen virulence. It is possible to transform plant-based feed ingredients to produce vaccines against important diseases and these could be fed directly to animals. Nutrients and nutricines contribute to three major factors important in the diet-host interaction; maintenance of gastrointestinal integrity, support of the immune system and the modulation of oxidative stress. Nutrition-based health is the next challenge in modern animal production and will be important to maintain economic viability and also to satisfy consumer demands in terms of food quality, safety and price. This must be accomplished largely through nutritional strategies making optimum use of both nutrients and nutricines.
\end{abstract}

Nutrition: Health: Disease: Animals

\section{Introduction}

Animal health in modern animal production is now a major challenge on a global basis as it impacts upon both human health and economics. First, and most important, there is the risk of zoonoses where animals can pass on diseases to man. Second, diseases such as BSE, foot and mouth disease and avian influenza are economically disastrous for the producer, consume public sector resources and disrupt international trade.

In reality, however, there are few options to manage animal health. Diseases such as necrotic enteritis in poultry and histomoniasis in turkeys were controlled in the recent past through various pharmaceutical products but most of these have now been banned in the European Union. Effective vaccines are available for some diseases but vaccination is not a suitable response for many devastating diseases such as avian influenza, BSE or post-weaning multi-systemic wasting disease. Consequently, mass culling programmes are frequently instituted to control animal diseases.

This focuses attention upon nutrition as the only practical solution to maintain animal health and therefore it is becoming increasingly evident that the feed and animal production industries must develop a nutrition-based health $(\mathrm{NbH})$ approach. This will require some radical re-thinking of nutrition and health interactions.
Formulation of modern animal feeds is currently based upon using an array of available ingredients that supply a desired nutrient profile at the minimum cost. The nutritional characteristics of the feed are derived from previous research and field observations in order to avoid deficiency symptoms and to support the economically important production criterion of interest. This production criterion may be: body weight, feed conversion efficiency, protein accretion, milk production or egg production which could be expected from healthy animals.

Criteria used to formulate animal feeds do not usually take account of the importance of nutrition in animal health, but focus on the productivity of healthy animals. Therefore to develop a positive $\mathrm{NbH}$ strategy it is necessary to consider the origins and types of diseases, and attempt to find nutritional solutions to support health maintenance and disease avoidance (Adams, 2002), whilst recognising that it is unlikely that simple therapeutic nutritional solutions will be found which will cure disease in sick animals.

Health or disease derives from a complex triad of interacting factors; diet, disease agent and host characteristics, as shown in Fig. 1 (Lavander, 1997).

Feed consumption in itself is a challenge to animal health as a potential route for the entry of pathogenic organisms and of mycotoxins into the body. Therefore good feed hygiene and feed manufacturing processes are clearly 


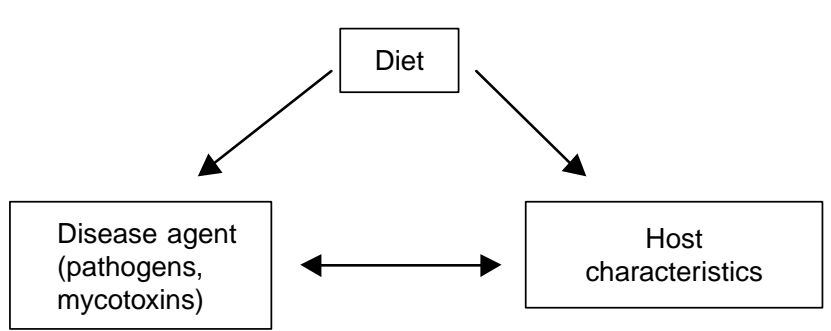

Fig. 1. Health-disease triad.

important to provide feed which is not a threat to animal health.

The nutritional status of the host plays an important part in determining resistance to infectious disease as exemplified by the effects of malnutrition in reducing immune responses or weakening physical barriers to infection. Diet also has an effect upon a whole host of non-infectious diseases which may be manifested as skeletal, cardiac and pulmonary problems.

Nutrition can directly affect the pathogen itself, since dietary regimens may exacerbate or mitigate the virulence of pathogenic organisms. Therefore the diet-pathogen interaction is of great importance in maintaining animal health. Diet plays a dual role in influencing the ability of the host to resist the pathogen and of modulating the virulence of the pathogen.

In intensive animal production the basic biochemical quality of feeds is readily manipulated and the amount of feed and frequency of feeding is usually controlled. This suggests that nutritional interventions to avoid disease and maintain health in animals should be more feasible than in the human scenario where control of food quality and quantity is inherently difficult. Therefore an understanding of the interactions between diet and pathogens and diet and animal host offers the possibility of introducing a concept of $\mathrm{NbH}$ for animal production.

\section{Diet-pathogen interactions}

Disease syndromes arise when pathogenic micro-organisms invade the gastrointestinal tract and ultimately the cells of the body of the animal. The basic objectives in the development of $\mathrm{NbH}$ must be to identify and to exploit various feed raw materials and other bioactive feed ingredients, nutricines (Adams, 1999, 2004), to inhibit pathogen growth and to ensure that the diet does not increase the virulence of pathogens.

\section{Inhibit pathogen growth}

Feed raw materials. There is scattered evidence that various feed raw materials have useful characteristics in terms of inhibiting growth of pathogens in the gastrointestinal tract of animals. Diets with low nutrient content, only $8.9 \%$ crude protein, compared with a standard of $18 \%$, and with high fibre remarkably reduced the severity of Escherichia coli enterotoxaemia in weaned pigs (Bertschinger et al. 1979). The addition of herring meal, which is a good source of digestible protein, neutralised the protective effect of the diet, suggesting that low protein in the diets was the important factor. High-protein diets are frequently not thoroughly utilised by the weaned pig during the digestion process. This leaves excess protein in the gastrointestinal tract which can be utilised by bacteria such as E. coli.

Post-weaning collibacillosis is a multifactorial disease of piglets and its expression is influenced by nutrition (Pluske et al. 2002). Feeding a diet based on cooked white rice and animal protein sources was very protective against the development of post-weaning collibacillosis (McDonald et al. 1999). A similar protective effect of cooked rice and animal protein was also seen in pigs experimentally infected with the intestinal spirochete Brachyspira hyodysenteriae, the agent of swine dysentery (Pluske et al. 1996). These results, however, could not be repeated in European studies (Lindecrona et al. 2003). In this study a diet based on cooked rice with a low content of NSP and resistant starch did not prevent the development of swine dysentery upon experimental challenge with $B$. hyodysenteriae. The best results were obtained from feeding a fermented liquid feed. However, more recent work, in this case with E. coli in piglets, again confirmed the beneficial effect of a cooked rice and protein diet (Montagne et al. 2004). In this study animal protein could also be replaced by plant protein and the protective effect of the diet did not diminish. Furthermore, addition of carboxymethylcellulose to cooked white rice increased digesta viscosity and enhanced the post-weaning collibacillosis, indicating that diet plays a role in the incidence of this enteric disorder.

The protective effects of these diets against bacterial infection have been attributed in part to the high digestibility of the carbohydrate in the boiled rice and of the animal protein (Pluske et al. 1996; McDonald et al. 1999). Nutrients from well-digested feed ingredients would be rapidly absorbed out of the gastrointestinal tract. This would limit the amount of fermentable substrate in the lower small intestine and reduce that entering the large intestine where the majority of the gastrointestinal microflora reside. This explanation is further supported by the results with carboxymethylcellulose. Increased viscosity of the digesta reduces the efficiency of digestion and absorption of nutrients and thus leaves more nutrients available for pathogenic bacteria.

Switching cattle feed from grain to hay was also associated with a reduction in E. coli $\mathrm{O} 157: \mathrm{H} 7$ (Callaway et al. 2003). This micro-organism is not a pathogen for cattle but causes haemorrhagic colitis in man which can be fatal. An abrupt switch in cattle feeding from grain to hay is in many cases not practical, even though there are clear human health benefits in terms of food safety. Nevertheless it does suggest future research strategies and indicates that nutritional solutions to such problems are possible.

A major food safety problem today is Campylobacter jejuni which is carried asymptomatically in the gastrointestinal tract of many food animals, particularly broiler chickens (Mead, 2002; Park, 2002). There is rapid horizontal transmission of Campylobacter in broiler flocks that leads to heavy contamination of broiler carcasses after processing (Shanker et al. 1990). Although Campylobacter is common in broilers, the origin of infection is still not 
clear. When feed was deliberately contaminated by Campylobacter and stored at room temperature, no culturable cells were recovered after $48 \mathrm{~h}$ (Mills \& Phillips, 2003), which suggests that survival of the organism in feeds is unlikely. Campylobacter is sensitive to desiccation, high $\mathrm{O}_{2}$ tension, and high and low temperatures. Consequently, modern feed manufacturing, transport and storage systems are unlikely to be congenial for Campylobacter. If it is not feed-borne, then general feed hygiene procedures may not solve the problem. Nevertheless the organism occurs in the gastrointestinal tract and probably feed-based treatments will be needed to control Campylobacter and improve food safety.

Feed raw materials have some effect upon Campylobacter (Udayamputhoor et al. 2003). Birds consuming feed made from plant-based protein sources - soyabean meal, rapeseed meal and maize-gluten meal - had less Campylobacter than birds consuming feed based on animal protein sources; meat meal, poultry by-product meal, fishmeal and feather meal (Table 1).

The lower level of colonisation in the birds fed plant protein may be explained in terms of a combined influence of various substrates in the diet. Plant protein-based feeds contain various NSP which may be fermented in the caeca into organic acids which would be detrimental to Campylobacter. $\mathrm{Fe}$ is an essential micronutrient for the growth of Campylobacter and plant-protein-based feeds are likely to be poorer in available Fe than animal-protein-based feeds.

Other plant materials, not commonly used in modern animal nutrition, such as leek, garlic and onion have antiCampylobacter effects (Lee et al. 2004). These data suggest that feed raw materials of plant origin might be useful in control of Campylobacter.

Nutricines. Animal feeds contain many bioactive components in additional to the classical nutrients and these have been referred to as food bioactives (Gillies, 2003), nonnutrient factors (Wiseman, 1999), or nutricines (Adams, 1999). Nutricines are increasingly being used in an $\mathrm{NbH}$ strategy. For example, organic acids such as formic, fumaric, lactic and propionic acids are able to inhibit pathogenic bacteria in a complex high-moisture environment such as occurs in the gastrointestinal tract of animals. They have been widely used in piglet feeds with good effect in terms of reducing gastrointestinal problems (Partanen \& Mrzoz, 1999). An important pathogen for pigs is Lawsonia intracellularis which causes proliferative enteropathy. Pigs given feed supplemented with $2.4 \%$ lactic acid had significantly reduced pathogenic lesions in the intestines 4

Table 1. Campylobacter shedding and intestinal contamination in broilers fed feeds from animal- or plant-based protein sources (from Udayamputhoor et al. 2003)

\begin{tabular}{lccc}
\hline & & \multicolumn{2}{c}{ Campylobacter counts } \\
\cline { 3 - 4 } Protein source & Shedding (\%) & Caecum & Jejuni \\
\hline Animal & 85.7 & 6.3 & 3.4 \\
Plant & 66.6 & 4.9 & 2.8 \\
\hline
\end{tabular}

weeks post-infection (Boesen et al. 2004), although lactic acid was not able to reduce infection with $B$. hyodysenteriae (Lindecrona et al. 2003).

Turkey poult enteritis and mortality syndrome is a major economic threat to turkey production in the USA. The syndrome is caused by agents such as bacteria and viruses that irritate and injure the intestines of young turkeys. An immune dysfunction is also frequently associated with poult enteritis and mortality syndrome which increases susceptibility to secondary bacterial infections that ultimately kill the poult. Treatment of feed for turkey poults with a propionic acid-based mixture at $1.25 \%$ did not prevent the disease occurring in the poult enteritis and mortality syndrome-challenged poults. However, it did reduce the cumulative mortality by $50 \%$ (Fig. 2) (Roy et al. 2002), and produced a delay in the onset of the initial mortality spike. The addition of organic acids at $1.25 \%$ to the feed would decrease the microbial contamination in the feed and also decrease the bacterial load in the intestine and caeca. Therefore, it is likely that the overall pathogenic challenge to the birds was decreased and this may have resulted in the reduced mortality shown in Fig. 2.

Organic acids, routinely used in a wide variety of poultry and pig feeds to alleviate various enteric problems, are frequently described as 'acidifiers', but this is in reality a misnomer. Organic acids in feed only slightly reduce the $\mathrm{pH}$ of the feed and they do not dramatically shift the $\mathrm{pH}$ of the gastrointestinal tract which is a highly buffered system. This is illustrated in Table 2, where feeds with either $1.5 \%$ fumaric or $1.5 \%$ citric acid were given to piglets (Risley et al. 1991). The organic acids did not reduce the $\mathrm{pH}$ in either the gastric digesta or in the digesta of the other intestinal sections. These observations were confirmed by Canibe et al. (2005) who found that the $\mathrm{pH}$ of the digesta from pigs given feed with $1.8 \%$ formic acid was only slightly reduced in the stomach but not in the rest of the gastrointestinal tract. Clearly the beneficial effect of organic acids in terms of animal growth and performance is not due to an acidification per se of the digesta in the gastrointestinal tract. Nevertheless these nutricines still exert an influence upon pathogenic bacteria resident in the gastrointestinal tract.

The precise mode of action of these acids as antimicrobials is still not established (Cherrington et al.

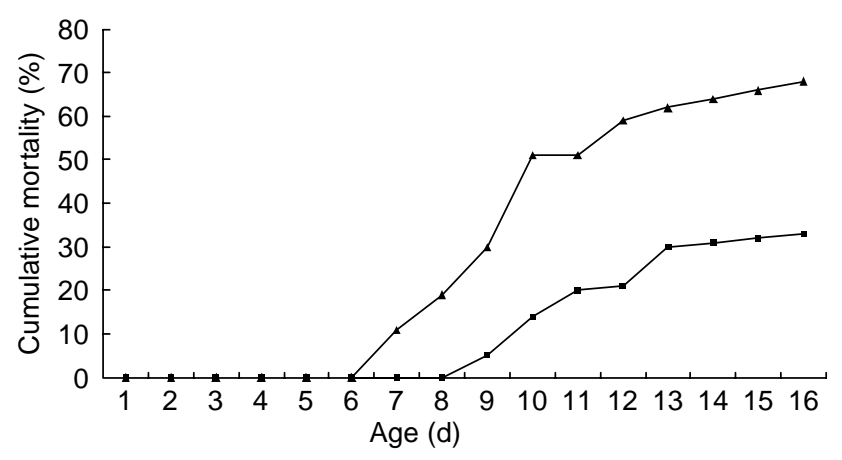

Fig. 2. Percentage cumulative mortality for poults challenged with poult enteritis and mortality syndrome (PEMS; $-\boldsymbol{-}-$ ) on day 6 and for those challenged with PEMS and supplemented with organic acids at $1.25 \%(--)$ on day 6 (from Roy et al. 2002). 
Table 2. Gastrointestinal pH in 8-week-old piglets given either 1.5\% fumaric or $1.5 \%$ citric acids in feed (from Risley et al. 1991)

\begin{tabular}{lccc}
\hline & \multicolumn{3}{c}{ Treatment } \\
\cline { 2 - 4 } Section of gastrointestinal tract & Control & Fumaric acid & Citric acid \\
\hline Stomach & 4.73 & 4.30 & 4.83 \\
Jejunum & 7.06 & 7.01 & 7.00 \\
Caecum & 5.96 & 6.04 & 6.05 \\
Lower colon & 6.51 & 6.53 & 6.47 \\
\hline
\end{tabular}

1990). At low external $\mathrm{pH}$ values the undissociated organic acid molecule is lipophilic and readily enters the microbial cell and then dissociates into a proton and anion. Both the protons and the anions have inhibitory effects upon the microbial cell which include provoking a collapse of the cell membrane potential (Eklund, 1985) and reduction in the rates of RNA, DNA, protein, lipid and cell-wall synthesis (Cherrington et al. 1990). However, in the gastrointestinal tract distal to the stomach the $\mathrm{pH}$ of the digesta (Table 2) is above the general $\mathrm{pKa}$ of the organic acids and so perhaps the effect is due more to the effects of the anions.

Another route to reduce E. coli $\mathrm{O} 157: \mathrm{H} 7$ populations in live animals is by feeding sodium chlorate (Edrington $e$ al. 2003). The enzyme nitrate reductase, which is present in E. coli, will use chlorate as an analogue of nitrate. The chlorate will be reduced to the toxic metabolite chlorite which kills the bacterial cells. A chlorate-based product has been successfully tested against Salmonella contamination in broilers (Byrd et al. 2003). Sodium chlorate has low toxicity for animals but such a nutritional strategy would probably face serious regulatory obstacles.

Rapid digestion and absorption of nutrients is certainly an important aspect of $\mathrm{NbH}$ as this reduces the amount of substrate remaining in the gastrointestinal tract which could be used by pathogenic micro-organisms. Considerable progress has already been made in this area with enzymes (Bedford, 2000) and lysophospholipids (Schwarzer \& Adams, 1996; Xing et al. 2004). Lysophospholipid supplementation of pig diets significantly improved the digestibility of DM, crude protein and energy (Dierick \& Decuypere, 2004). Xylanase supplementation of wheatbased broiler feed significantly reduced the Campylobacter counts in the caecum to about 10000 colony-forming units/g but this was not sufficient to improve food safety (Fernandez et al. 2000). Layer hens, which were experimentally infected with $B$. intermedia, showed reduced faecal excretion of the micro-organism when fed a wheat-based diet supplemented with a commercial enzyme product (Hampson et al. 2002).

\section{Modulation of pathogen virulence}

Infectious diseases occur after invasion of the host by a pathogenic micro-organism. However, the mere presence of an infectious micro-organism in the body of an animal does not necessarily result in subsequent development of disease. Diet and the nutritional status of the host have an impact upon the degree of virulence of pathogenic microorganisms.
Necrotic enteritis and Clostridia perfringens. Many clostridial species secrete powerful toxins that cause serious diseases in man and animals, such as tetanus, botulism, gas gangrene and necrotic enteritis. In particular, Clostridia perfringens is an important pathogen of poultry and, if not controlled, causes necrotic enteritis in chickens, turkeys, and geese (van Immerseel et al. 2004). The disease syndrome generates lesions in the wall of the small intestine which in turn leads to loss of appetite, the production of dark-coloured faeces, poor growth and possibly mortalities of $25-50 \%$.

Clostridial bacteria, however, commonly occur in healthy chickens but the $\mathrm{pH}$ and high $\mathrm{O}_{2}$ content of the small intestine do not support extensive growth of the organism. For disease symptoms to appear there must be some stress or trigger factor that allows the clostridial bacteria to proliferate and migrate to the lower part of the small intestine.

Several stresses predispose birds to necrotic enteritis; damage to the intestinal lining by coccidia or by other bacteria, immunosuppression and feed characteristics. Wheat and barley as major raw materials in poultry diets increased the prevalence of necrotic enteritis in broilers compared with the use of maize-based diets (Branton et al. 1987). Use of all wheat in the diet increased mortality attributed to necrotic enteritis, by six to ten times that experienced when only maize was used in the diet (Table 3). Birds that consumed the diet containing approximately equal quantities of wheat and maize exhibited intermediate mortality.

The precise reason why wheat predisposes poultry to necrotic enteritis is not clear. Branton et al. (1996) studied pentosan extracts of wheat and concluded that the water-soluble pentosans of wheat did not directly increase the growth of $C$. perfringens.

Control of necrotic enteritis in poultry production remains an important health issue. In the recent past a useful anti-clostridial agent used in feeds was the antibiotic growth promoter avoparcin, but this has now been prohibited from use in the European Union. Consequently there is considerable interest in developing strategies to minimise the stresses on the birds which could predispose them to necrotic enteritis. Moving to a maize-based diet is not possible in many parts of the world and this alleviates but does not control the problem. It is probably important to maintain a healthy, stable gut environment in poultry and to reduce the overall microbial, chemical and physical stress

Table 3. Effect of cereal type on performance of broilers at age $42 \mathrm{~d}$ infected with necrotic enteritis (from Branton et al. 1987)

\begin{tabular}{lcccr}
\hline & & & \multicolumn{2}{c}{ Mortality } \\
\cline { 3 - 5 } Cereal & Weight $(\mathrm{kg})$ & $\begin{array}{c}\text { Feed:gain } \\
\text { ratio }\end{array}$ & Incidence & $\%$ \\
\hline Maize & $1.749^{\mathrm{a}}$ & $1.946^{\mathrm{a}}$ & $12 / 420^{\mathrm{a}}$ & $2 \cdot 9$ \\
Wheat & $1.659^{\mathrm{a}}$ & $1.861^{\mathrm{b}}$ & $101 / 350^{\mathrm{b}}$ & 28.9 \\
Maize and & $1.757^{\mathrm{a}}$ & $1.871^{\mathrm{b}}$ & $44 / 350^{\mathrm{c}}$ & 12.6 \\
$\quad$ wheat & & & &
\end{tabular}

a,b,c Values within a column with unlike superscript letters were significantly different $(P<0.05)$ 
on the birds. Fungal contamination of feeds must be controlled to avoid mycotoxin formation and subsequently immunosuppression. Use of well-stabilised oils and fats in feed manufacture will reduce oxidative stress. Physical consistency of feed characteristics is important so as not to irritate the gut wall. There still remains a need for an effective nutritional solution to necrotic enteritis in poultry.

Coxsackievirus and myocarditis. Studies on the aetiology of Keshan disease in China indicated that both an Se deficiency and Coxsackievirus were necessary components of the disease (Beck et al. 1994). Furthermore, the phenotype of the virus was altered in mice suffering from nutritional deficiencies in either vitamin $E$ or Se such that a non-pathogenic strain of the virus became pathogenic and remained so even when inoculated into nutrient-sufficient mice (Table 4) (Beck, 1997).

More detailed work indicated that the change in phenotype of the virus was due to a change in genotype. Therefore the nutrition of the host had a direct impact in terms of virulence of a potential pathogen, which suggests that nutrition is a possible mechanism for driving viral evolution and thus creating altered viruses with different phenotypic properties. This may contribute to further evolution of new and emerging pathogens.

Iron and infection. Normal healthy animals have many effective mechanisms of natural resistance to infection but these protective systems only function successfully in an environment where the normal concentration of free $\mathrm{Fe}$ is virtually zero (Bullen et al. 2005). This low-Fe environment is maintained by the Fe-binding proteins transferrin and lactoferrin which are normally only $30-40 \%$ saturated with Fe.

Freely available $\mathrm{Fe}$ diminishes or destroys normal resistance to infection and increases bacterial virulence. This has been demonstrated with Vibrio vulnificus in mice (Wright et al. 1981). The injection of ferric ammonium citrate dramatically reduced the LD50 from $6 \times 10^{6}$ to one organism in mice. The replication and virulence of Mycobacterium tuberculosis (Cronje et al. 2005) and of M. bovis (Denis \& Buddle, 2005) was influenced by Fe and Fe-chelating agents. The Fe chelator, desferrioxamine, consistently reduced the viability of $M$. tuberculosis (Cronje et al. 2005) and addition of lactoferrin to macrophages infected by $M$. bovis blocked replication of the pathogen (Denis \& Buddle, 2005). The important pathogen Campylobacter has several genes regulating $\mathrm{Fe}$ acquisition and oxidative stress, which indicates the central role that $\mathrm{Fe}$ plays in the virulence of this organism (van Vliet et al.

Table 4. Incidence of heart lesions in mice inoculated with a non-pathogenic strain of Coxsackievirus recovered from selenium- or vitamin E-adequate or deficient mice (from Beck, 1997)

\begin{tabular}{lc}
\hline Diet fed donor mice & Incidence of heart lesions \\
\hline Lard + Se + vitamin E & $0 / 10$ \\
Lard - Se + vitamin E & $8 / 10$ \\
Lard + Se - vitamin E & $9 / 10$ \\
\hline
\end{tabular}

2002). The ability of freely available Fe to diminish or destroy normal resistance and to increase bacterial virulence has been demonstrated in at least eighteen different bacterial species (Bullen et al. 2005).

Excessive dietary $\mathrm{Fe}$ induced a normally benign Coxsackievirus to damage heart muscle in mice (Beck et al. 2005). High dietary Fe gave a similar response to that seen with deficiencies of antioxidants such as vitamin $\mathrm{E}$ and Se (Beck, 1997). The highest heart viral titres were found in mice fed a diet deficient in vitamin $\mathrm{E}$ with excess $\mathrm{Fe}$ which was also the most pro-oxidative diet. However, oxidative stress is not the full explanation since the formation of oxidised products, assayed as thiobarbituric acid reactive substances, in the liver of the mice did not always correlate with the extent of heart damage.

The control of free Fe is important for health maintenance and disease avoidance and organic acids may play a role here. Many organic acids such as lactic, fumaric and citric acids can form complexes with Fe. Phytic acid, which is a common constituent of plant seeds, and therefore also of animal feeds, is a powerful Fe chelator. Possible beneficial effect of organic acids in animal nutrition may be related to their antimicrobial activity and their ability to reduce oxidative stress through Fe chelation.

\section{Diet-mycotoxin interactions}

Mycotoxins are potent, toxic molecules, produced by moulds growing on feed raw materials and feeds. Many mycotoxins have damaging cytotoxic properties which seriously affect animal health manifested as reduced growth performance or increased mortality. Mycotoxins are also immune suppressors which will increase the susceptibility of the animals to opportunistic infections in the environment (Li et al. 2000a,b).

There are currently three nutritional solutions to deal with mycotoxins. First, mould growth in feed raw materials and in feeds should be minimised so that the prevalence of toxigenic moulds is reduced. Second, dietary interventions may reduce the toxic effects of mycotoxins. Third, mycotoxin-binding nutricines can be incorporated into feeds to reduce the absorption of the toxins into the body of the animal.

Mycotoxins only occur if there has been mould contamination of raw materials or feeds, and the first line of defence is to reduce mould contamination and growth to the minimum. The judicious use of organic-acid-based mould inhibitors can prevent excessive mould contamination and reduce existing mould levels. This can be very important in raw materials that are stored for some time. The most effective products need to be based on propionic acid. Formic acid is not as inhibitory to mould growth as is propionic acid and may allow aflatoxin production in stored materials (Holmberg et al. 1989). Inoculation of moist barley with Aspergillus parasiticus and treatment of the barley with formic acid ( $5 \mathrm{~kg} /$ tonne) promoted the development of aflatoxin above the control, whereas treatment with propionic acid ( $3 \mathrm{~kg} /$ tonne) completely inhibited mycotoxin production. Many proprietary mould inhibitors based on propionic acid and its salts are available and effectively reduce mould contamination in feeds. 
However, the complete elimination of mycotoxins present in animal feeds is not a practical possibility. Therefore various dietary interventions have been considered to ameliorate the effects of mycotoxins in the animal. Antioxidants, butylated hydroxyanisole (BHA) and butylated hydroxytoluene, inhibit aflatoxin carcinogenesis in animals. Treatment of rats with BHA greatly reduced the liver carcinogenic effect of aflatoxin (Monroe et al. 1986). The production of protective enzymes was induced by BHA which increased the biliary excretion of an aflatoxin glutathione conjugate so less aflatoxin was left in the liver and more was excreted in the urine (Table 5). The binding of aflatoxin to liver DNA was also greatly reduced by BHA which is important in the liver carcinogenic effect of aflatoxin.

Supplementation of turkey feeds with the antioxidant butylated hydroxytoluene prevented the toxic effects of aflatoxin $\mathrm{B}_{1}$ (Coulombe et al. 2005). The mechanism of protection was primarily through inhibition of enzymic activation of aflatoxin in the liver. Rather high levels of butylated hydroxytoluene of $4 \mathrm{~kg} /$ tonne were utilised which would have serious practical implications.

Administration of $\mathrm{N}$-acetylcysteine, an acetylated derivative of the amino acid cysteine, prevented the effects of aflatoxin toxicity on weight gain and diminished the severity of histological lesions in broilers (Valdivia et al. 2001). $\mathrm{N}$-acetylcysteine has been widely prescribed to human subjects in several countries and therefore its safety and pharmacological properties are well established. It is an excellent source of sulfhydryl groups and is capable of stimulating synthesis of glutathione which is also probably involved in reducing the effects of mycotoxins. $\mathrm{N}$-acetylcysteine may be a very useful compound to control aflatoxicosis in broilers.

A third strategy to mitigate the adverse effects of mycotoxins is to incorporate an inert mycotoxin-binding material into the feeds. This prevents their absorption into the animals' body and nullifies the toxic properties of the mycotoxins. This strategy has been the subject of considerable research in recent years. Various absorbing materials have been used including charcoal, zeolites, bentonite, spent bleaching clay from vegetable oil refining, and hydrated sodium calcium aluminosilicate (Schell et al. 1993; Ramos \& Hernandéz, 1997; Bailey et al. 1998). The main problem is that mycotoxins are chemically quite diverse and so no single toxin-binding compound will be effective for all mycotoxins. Nevertheless there are several proprietary products used as mycotoxin binders and this may be a useful nutritional strategy if feeds contaminated with mycotoxins have to be used.

Management and control of mycotoxins is technically well established. This will become a very important part of

Table 5. Distribution of aflatoxin in the rat $2 \mathrm{~h}$ after dosing (from Monroe et al. 1986)

\begin{tabular}{lcc}
\hline Treatment & $\begin{array}{c}\text { Liver } \\
\text { (\% of dose) }\end{array}$ & $\begin{array}{c}\text { Urine } \\
\text { (\% of dose) }\end{array}$ \\
\hline Control & 18.2 & 0.35 \\
Butylated hydroxyanisole & 9.6 & 3.03
\end{tabular}

$\mathrm{NbH}$, particularly since mycotoxins pose a threat to the immune system of animals, and a strategy of health maintenance and disease avoidance must ensure that animals have an optimum immune system.

\section{Diet-host interactions}

As illustrated in Fig. 1, diet influences animal health by two major interactions. Diet has a very significant effect upon disease agents, such as the growth and virulence of pathogens and on mycotoxins as described earlier. However, diet also contributes to $\mathrm{NbH}$ through at least three specific diet-host interactions:

(1) maintenance of gastrointestinal integrity;

(2) support of the immune system;

(3) modulation of oxidative stress.

There may well be different threshold levels of nutrients and nutricines required to fulfil these various functions. A threshold level of a nutrient or a nutricine will lie between the minimum requirement and the maximum tolerance. The minimum requirement will be the smallest amount that an animal must consume to avoid deficiency symptoms. This is only applicable to essential nutrients and is of little relevance in $\mathrm{NbH}$. The maximum threshold level will be the largest amount an animal can consume without an adverse effect. All dietary components, both nutrients and nutricines, will have a maximum threshold level at which they will lead to a nutritional imbalance or even toxicity. An alternative strategy is to define nutritional requirements in terms of the amount of nutrients and nutricines to maintain genomic stability (Fenech, 2002, 2003). It should be relatively easy to determine new nutritional standards for animals based on maintenance of genomic stability for disease avoidance, since animals usually receive feed made according to a known formulation, which can be readily modified, and the total feed intake is under good control.

\section{Maintenance of gastrointestinal integrity}

The gastrointestinal tract is probably the most important organ in an animal and it is an interface with the environment, as the inside of the gastrointestinal tract is still outside the body of the animal. Maintenance of the health of the gastrointestinal tract is extremely important and very complex. It relies on a delicate balance between the diet, the commensal microflora and the mucosa, including the digestive epithelium and the overlying mucus layer. The cells of the gastrointestinal tract are also the last line in the body's defence against pathogenic bacteria and toxins arriving in feed or water. Feed ingredients, as well as toxins and micro-organisms, frequently damage the structure of the gastrointestinal tract. This leads to various enteric disease problems manifested as malabsorption of nutrients, diarrhoea and wet litter, and increased risk of invasion of the body by pathogens. Therefore it is very important to develop nutritional strategies which maintain gastrointestinal integrity.

Several amino acids are known to play an important role in maintaining the integrity of the gastrointestinal tract. Glutamine is important in maintaining the gastrointestinal 
mucosa and it prevented damage to the villi during the first week post-weaning in piglets (Wu et al. 1996). Arginine plays an important role in tissue repair and immune cell function (Corzo et al. 2003). Butyric acid is an important energy source for enterocytes in the gastrointestinal tract. Butyrate also has a potent anti-inflammatory effect both in vivo and in vitro (Akira et al. 1999). Unfortunately the high cost of glutamine and arginine limits their application in animal feeds, although butyric acid and its salts are currently used in some feed formulations.

\section{Support the immune system}

The policy of eradication of animal diseases through hygiene and slaughter strategies brings an associated risk that livestock become naïve to certain pathogens and as a consequence susceptible to epidemic outbreaks. Therefore immunomodulation measures in food animals will remain extremely important in maintenance of animal health. In particular there will be more emphasis on mucosal immunity and the activation of the innate immune system through nutritional strategies.

There is a reciprocal interaction between diet and the immune system, as nutrition modulates the immune system and the immune system responses modulate nutritional needs. Various components in feed such as mycotoxins, bacteria, viruses and nutricines have an important influence upon the immune system. The multi-systemic wasting disease of pigs is a condition associated with immune responses and a virus. Mycotoxins as discussed earlier are widely recognised as suppressing the immune system (Li et al. 2000a,b). This makes animals more susceptible to secondary infections or to sub-clinical infections and gives poor response to vaccines.

Immunomodulation is an important but delicate aspect of animal production as it requires the avoidance of immunosuppression which would expose the animal to infectious disease, yet it must also avoid excessive activation of the immune system as that is growth-inhibiting. Activation of the immune system may occur during disease challenge or exposure to a high microbial burden in an unhygienic environment. There are several important physiological consequences of this activation of the immune system: production of pro-inflammatory cytokines, fever, reduced appetite, amino acid resorption from muscle and the redirection of nutrients from accretion in meat and milk towards liver anabolism of acute-phase proteins.

Large-molecular-weight compounds such as polysaccharides, proteins, glycopeptides and nucleotides have been identified as having immunomodulatory properties. $\beta$-Glucans from yeast cell walls are already used in aquaculture as immunostimulants and have also been shown to up regulate the innate immune response in immature chickens against Salmonella (Lowry et al. 2005). Various antioxidants, in particular the carotenoids (Chew, 1993; Blount, 2004), and tocopherols are valuable in supporting the immune system. The yellow carotenoid, lutein, modulates cell-mediated and humoral immune responses in cats (Kim et al. 2000a) and in dogs (Kim et al. 2000b). Dietary lutein may enhance the antibody response of dogs given routine vaccinations. There is evidence of an immune response to lutein in avian species (Blount et al. 2003). Zebra finches were given a high-lutein diet and then challenged with the lectin phytohaemagglutinin. This lectin induces a cell-mediated immune response which can be measured as a swelling on the skin of the bird. Birds on lutein-supplemented diets produced a significantly larger immune response than control birds (Fig. 3). This suggests that immune function may be limited by carotenoid availability in the diet. Many poultry feeds, particularly in Europe, will be extremely low in carotenoid content as they are frequently based on wheat and barley and such diets may not support an optimum immune system.

Immunomodulation will become a very important part of an $\mathrm{NbH}$ strategy in the future, as animal health will need to be maintained without large-scale medication programmes. The challenge will be to identify those nutricines which have a beneficial effect in supporting the immune system. Clearly, lutein is likely to be one important nutricine in this respect.

Plant-based edible vaccines. Vaccination is widely used in modern animal production to protect against many diseases and is an important strategy in health maintenance and disease avoidance. It is possible to generate vaccines in transgenic plants and this could be very valuable in an $\mathrm{NbH}$ programme for animals.

Vaccine production in transgenic plants has several major advantages compared with classical vaccination use. These include a lower cost of production and probably more stable vaccines as they would be stored in cells of the host plant. Such vaccines would also be free from animal pathogens such as prion proteins. Delivery to animals would be simple as the plant containing the vaccine could be simply incorporated into the standard animal feed.

An example of a plant-based edible vaccine is the utilisation of the Norwalk virus capsid protein expressed in potatoes as an antigen (Tacket et al. 2000). When the transgenic potatoes were fed to human volunteers, nineteen of the twenty subjects developed an immune response to the antigen. This confirmed that foreign proteins can be immunogenic when presented to the mucosal immune system via an orally delivered transgenic potato. A multicomponent plant-based vaccine comprised of cholera toxin complementary DNA fused to a rotavirus enterotoxin and enterotoxigenic $E$. coli fimbrae antigen genes was expressed in transgenic potatoes (Yu \& Langrióge, 2001). When the

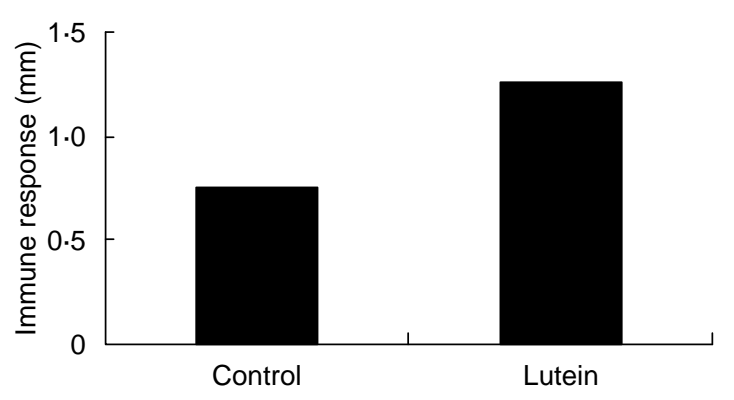

Fig. 3. Effect of lutein supplementation of feed on the immune response (measured as a swelling on skin in $\mathrm{mm}$ ) (from Blount et al. 2003). 
transgenic potatoes were used to orally immunise mice there were detectable levels of serum and intestinal antibodies against the pathogen antigens. Diarrhoea symptoms were reduced in severity and duration in passively immunised mouse neonates following rotavirus challenge. Plant-based edible vaccines can offer simultaneous protection against infectious virus and bacterial diseases. Further confirmation of the potential and versatility of plant-based edible vaccines has been provided in studies with hepatitis B surface antigen expressed in transgenic potatoes (Kong et al. 2001). Mice fed the transgenic potatoes produced serum antibodies that exceeded the protective level and, on parenteral boosting, generated a strong long-lasting secondary antibody response.

Of more direct relevance to animal health is the production of a vaccine against porcine epidemic diarrhoea virus in transgenic tobacco plants (Bae et al. 2003). This virus is highly contagious and porcine epidemic diarrhoea virus causes enteritis in pigs at all ages and is often fatal in neonatal piglets. Transgenic tobacco plants were simply lyophilised, ground to a fine powder, suspended in a buffer and fed directly to mice. As shown in Fig. 4, higher levels of antigenspecific IgA were detected in faecal samples collected from mice fed antigen-expressing transgenic tobacco $v$. control mice. There was also a dose-response since higher levels of antigen-specific IgA were found in faecal samples of mice fed $5 \mathrm{mg}$ plant material compared with those fed $1 \mathrm{mg}$. Feeding mice with a plant-based edible vaccine induced an efficient antigen-specific mucosal immune response.

Plant-based edible vaccines would be highly desirable for use in animal production. In particular they may offer an enhanced immune response at mucosal sites, including the production of secretory $\operatorname{IgA}$, which serves as a defence against pathogen colonisation and infection by preventing the specific interaction of pathogens with mucosal surfaces. There are many important pathogens of animals that cause enteric or respiratory diseases and therefore the mucosal response is an essential first line of defence. Furthermore, potential low cost and ease of administration to animals makes this a very attractive concept for an $\mathrm{NbH}$ programme.

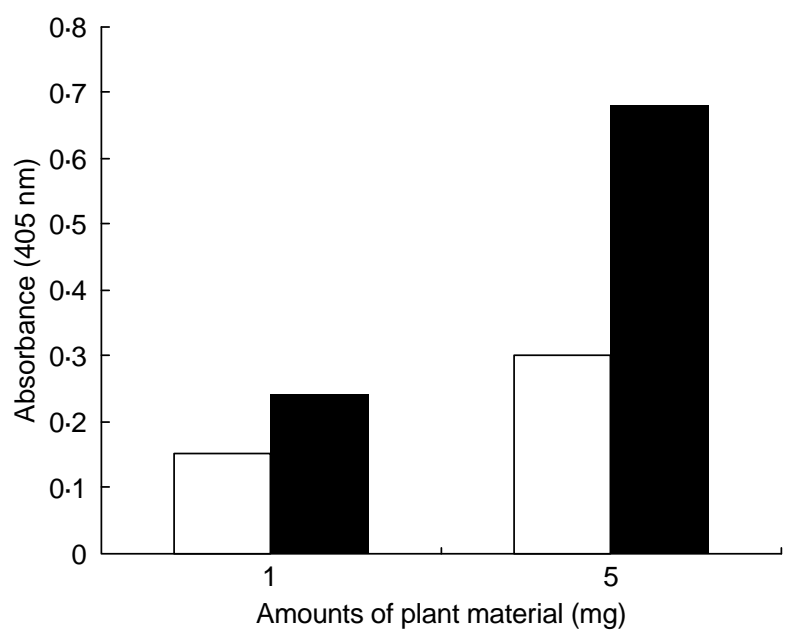

Fig. 4. Level of $\lg A$ specific to the antigen after feeding mice either control tobacco $(\square)$ or vaccine-containing transgenic tobacco ( $\square$ (from Bae et al. 2003).

\section{Modulate oxidative stress}

During the normal respiration process of animals, $\mathrm{O}_{2}$ is progressively reduced to yield water. However, the incomplete reduction of $\mathrm{O}_{2}$ during this process leads to the formation of chemical entities that have powerful oxidising properties. These are known as reactive oxygen species (ROS) and basal cellular metabolism in the body of an animal continuously produces ROS. The concept of oxidative stress, when ROS accumulate in the body, is becoming very important in medical and nutritional research. It may be responsible for an extremely broad spectrum of disease syndromes in man and animals. These diseases are known as non-infectious or metabolic diseases. In general they are diet related and so nutrition plays an important role in controlling and mitigating these diseases.

Oxidative stress is also becoming increasingly implicated in the onset of infectious diseases. This has already been discussed in terms of modifying the virulence of Coxsackievirus (Beck et al. 1994) but ROS may also be involved in the pathogenesis of several viral diseases (Peterhans, 1997). The ROS are key participants in damage caused by viral infection such as inflammation of epithelial cells and they have been implicated in the pathogenesis of influenza (Peterhans et al. 1987; Hennet et al. 1992). When mice were infected intranasally with influenza virus, systemic effects of the infection were dramatic, culminating in death after $5-6 \mathrm{~d}$. Cells lavaged out of the lungs of infected mice showed an increased production of singlet oxygen and a reduced concentration of the antioxidants $\alpha$-tocopherol, ascorbate and glutathione. Changes in the concentrations of antioxidants in the liver were also noticed in the early stages of infection and this may reduce the ability of the animals to resist an oxidative stress and exacerbate the generation of ROS. Supplementation with excess vitamin E (500 parts per million for 6 weeks) of old mice reduced influenza lung titres 25-fold when compared with mice fed the control diet (Hayek et al. 1997). Young mice responded less dramatically but $5 \mathrm{~d}$ after infection still showed a 15 -fold reduction in virus titres in lung tissue. In this instance high levels of antioxidant nutricines exerted a therapeutic effect and reduced the amount of virus in the tissues. These observations suggest that infection was associated with an oxidative stress and, in the light of current concerns about avian influenza, they may be quite important. It would certainly be interesting to ascertain whether or not significant levels of dietary antioxidants would assist in the resistance of animals to viral diseases.

The gastrointestinal mucosa is constantly exposed to a variety of pro-oxidants derived from ingested food materials. In addition the mastication and digestion of lipid-containing foods in the gastrointestinal fluids can induce lipid peroxidation due to the exposure of unsaturated lipids to catalytic haem or non-haem Fe. Dietary Fe remains substantially unabsorbed in the gastrointestinal tract and may support bacterial infection as previously discussed and may also be involved in the generation of hydroxyl radicals by a Fenton-type reaction in conjunction with colonic microflora. Phytic acid and its hydrolysis products, which are chelators, exert a protective effect on Fe-induced lipid peroxidation (Miyamoto et al. 2000). This raises questions 
about the effect of using exogenous phytase in animal feeds for the purpose of hydrolysing phytic acid to release available P. It may be that phytic acid plays a useful role as a natural antioxidant. Therefore supplementation of feeds with exogenous phytase might require further consideration of antioxidant levels in the feed. The natural antioxidant quercetin, for example, protected rat mucosal intestinal tissues against Fe-induced lipid peroxidation (Murota et al. 2004), so alternative antioxidant systems are feasible.

There is some evidence that the damage caused by mycotoxins is also a form of oxidative stress due to the stimulation of lipid peroxidation in the liver (Rizzo et al. 1994). This may explain the beneficial effect seen with antioxidants such as BHA in mitigating the adverse effects of mycotoxins (Monroe et al. 1986).

In the chick embryo there is considerable metabolism of unsaturated fatty acids which are prone to auto-oxidation and subsequent oxidative stress. At hatching the chick is suddenly exposed to atmospheric $\mathrm{O}_{2}$ and has a dramatic increase in metabolic rate. The brain of the day-old chick is highly enriched in long-chain PUFA $\left(\mathrm{C}_{20}\right.$ and $\left.\mathrm{C}_{22}\right)$, and the liver also has a large concentration of unsaturated fatty acids (Surai et al. 1996). It is highly likely that lutein and tocopherol in egg yolk play an important role as antioxidants in reducing oxidative stress during the hatching phase. As mentioned previously, lutein contents of eggs in modern poultry production are usually quite low and therefore lutein levels in feeds probably need to be reconsidered from an animal health point of view.

Ascites is a non-infectious disease in broilers and a major cause of economic losses. The syndrome is a basic problem of $\mathrm{O}_{2}$ supply and demand that develops in response to cardiopulmonary insufficiency. There has been considerable interest in the relationship between ascites and vitamin $\mathrm{E}$ in broilers. Oxidative stress has been implicated in the malfunctioning of mitochondria from lungs of broilers suffering ascites and the syndrome could be alleviated by high levels of dietary vitamin E (Iqbal et al. 2001). Dietary coenzyme $\mathrm{Q}_{10}$, which is a component of the mitochondrial respiratory chain, has a beneficial effect in reducing ascites mortality in broilers (Geng et al. 2004). Antioxidant nutricines are certainly important components of $\mathrm{NbH}$ because they influence so many factors related to health. They play a role in maintaining good feed quality by avoiding oxidation of feed ingredients, they protect the animal against non-infectious diseases and through immunostimulatory effects they also help against infectious diseases.

\section{Conclusions}

Animal health is an extremely important factor both in food security and in human health. Events such as BSE, foot and mouth disease and avian influenza illustrate just how important is the maintenance of animal health. Furthermore, these examples also illustrate the difficulty of dealing with such problems where mass culling of millions of animals at great effort and expense has been the only practical solution. There is clearly a need to develop a general $\mathrm{NbH}$ strategy where animal feeds are designed to influence health maintenance and disease avoidance. This would be of both practical and economic benefits if it reduces disease incidence.
There are several important diet-health interactions which need further exploration. There is already considerable evidence to suggest that animal feeds can be constructed to inhibit growth of pathogens and reduce pathogen virulence. They can modulate the microflora of the gastrointestinal tract and alleviate enteric disorders. Various nutricines can reduce the risk of toxins in feeds and assist with digestion and utilisation of nutrients. Antioxidant nutricines are important in reducing oxidative stress and in supporting the immune system. The introduction of plantbased vaccines would offer further advantages in terms of infectious disease control.

The nutrient requirements allocated to various animal species have usually been developed based on the avoidance of deficiency diseases and the necessity for rapid growth and productivity of the animals. Now they need to be directed towards health maintenance and disease avoidance. Moreover, nutrient requirement only covers the basic essential nutrients and there is very little information on the most useful level of various nutricines such as organic acids, antioxidants, enzymes and carotenoids. In fact, the practical inclusion rate of various nutricines in animal feeds is more likely to be dictated by legislation than by scientific requirements.

To develop feed formulations designed for an $\mathrm{NbH}$ strategy, a maximum threshold level of both nutrients and nutricines will need to be established rather than focusing on minimum levels. This will be the largest amount an animal can consume without an adverse effect. Once the maximum threshold levels are known it should be possible to design an effective $\mathrm{NbH}$ strategy which is clearly the next challenge in modern animal production.

\section{References}

Adams CA (1999) Nutricines. Food Components in Health and Nutrition. Nottingham, UK: Nottingham University Press.

Adams CA (2002) Total Nutrition. Feeding Animals for Health and Growth. Nottingham, UK: Nottingham University Press.

Adams CA (2004) Nutricines in poultry production: focus on bioactive feed ingredients. Nutrition Abstracts and Reviews 74B, $1 \mathrm{~N}-12 \mathrm{~N}$.

Akira A, Bamba T \& Sasaki M (1999) Physiological and antiinflammatory roles of dietary fibre and butyrate in intestinal functions. Journal of Parenteral and Enteral Nutrition 23, S70-S73.

Bae J-L, Lee J-G, Kang T-J, Jang H-S, Jang Y-S \& Yang M-S (2003) Induction of antigen-specific systemic and mucosal immune responses by feeding animals transgenic plants expressing the antigen. Vaccine 21, 4052-4058.

Bailey RH, Kubena LF, Harvey RB, Buckley SA \& Rottinghaus GE (1998) Efficacy of various inorganic sorbents to reduce the toxicity of aflatoxin and T-2 toxin in broiler chickens. Poultry Science 77, 1623-1630.

Beck MA (1997) Increased virulence of Coxsackievirus B3 in mice due to vitamin $\mathrm{E}$ or selenium deficiency. Journal of Nutrition 127, S966-S970.

Beck MA, Kolbeck PC, Rohr LH, Shi Q, Morris VC \& Levander OA (1994) Increased virulence of a human enterovirus (coxsackievirus B3) in selenium-deficient mice. Journal of Infectious Diseases 170, 351-357.

Beck MA, Shi Q, Morris VC \& Levander OA (2005) Benign coxsackievirus damages heart muscle in iron-loaded vitamin 
E-deficient mice. Free Radical Biology and Medicine 38, $112-116$.

Bedford MR (2000) Exogenous enzymes in monogastric nutrition - their current value and future benefits. Animal Feed Science and Technology 86, 1-13.

Bertschinger HU, Eggenberger E, Jucker H \& Pfirter HP (1979) Evaluation of low nutrient, high fibre diets for the prevention of porcine Escherichia coli enterotoxaemia. Veterinary Microbiology 3, 281-290.

Blount JD (2004) Carotenoids and life-history evolution in animals. Archives of Biochemistry and Biophysics 430, 10-15.

Blount JD, Metcalf NB, Birkhead TR \& Surai PF (2003) Carotenoid modulation of immune function and sexual attractiveness in Zebra finches. Science 300, 125-127.

Boesen HT, Jensen TK, Schmidt AS, Jensen BB, Jensen SM \& Moller K (2004) The influence of diet on Lawsonia intracellularis colonization in pigs upon experimental challenge. Veterinary Microbiology 103, 35-45.

Branton SL, Lott BD, May JD, Hedin PA, Austin FW, Latour MA \& Day EJ (1996) The effects of nonautoclaved and autoclaved water-soluble wheat extracts on the growth of Clostridium perfringens. Poultry Science 75, 335-338.

Branton SL, Reece FN \& Hagler WM Jr (1987) Influence of a wheat diet on mortality of broiler chickens associated with necrotic enteritis. Poultry Science 66, 1326-1330.

Bullen JJ, Rogers HJ, Spalding PB \& Ward CG (2005) Iron and infection: the heart of the matter. FEMS Immunology and Medical Microbiology 43, 325-330.

Byrd JA, Anderson RC, Callaway TR, Moore RW, Knape KD, Kubena LF, Ziprin RL \& Nisbet DJ (2003) Effect of experimental chlorate product administration in the drinking water on Salmonella typhimurium contamination of broiler. Poultry Science 82, 1403-1406.

Callaway TR, Elder RO, Keen JE, Anderson RC \& Nisbet DJ (2003) Forage feeding to reduce postharvest Escherichia coli populations in cattle, a review. Journal of Dairy Science 86, $852-860$.

Canibe N, Hojberg O, Hosgaard S \& Jensen BB (2005) Feed physical form and formic acid addition to the feed affect the gastrointestinal ecology and growth performance of growing pigs. Journal of Animal Science 83, 1287-1302.

Cherrington CA, Hinton M \& Chopra I (1990) Effect of short-chain organic acids on macromolecular synthesis in Escherichia coli. Journal of Bacteriology 68, 69-74.

Chew BP (1993) Role of the carotenoids in the immune response. Journal of Dairy Science 76, 2804-2811.

Coulombe RA, Guarisco JA, Klein PJ \& Hall JO (2005) Chemoprevention of aflatoxicosis in poultry by dietary butylated hydroxytoluene. Animal Feed Science and Technology 121, 217-225.

Corzo A, Moran ET \& Hoehler D (2003) Arginine need of heavy broiler males: applying the ideal protein concept. Poultry Science 82, 402-407.

Cronje L, Edmonson N, Eisenach KD \& Bornman L (2005) Iron and iron chelating agents modulate Mycobacterium tuberculosis growth and monocyte-macrophage viability and effector functions. FEMS Immunology and Medical Microbiology 45, $103-112$.

Denis M \& Buddle BM (2005) Iron modulates the replication of virulent Mycobacterium bovis in resting and activated bovine and possum macrophages. Veterinary Immunology and Iтmunopathology 107, 189-199.

Dierick NA \& Decuypere JA (2004) Influence of lipase and/or emulsifier addition on the ileal and faecal nutrient digestibility in growing pigs fed diets containing $4 \%$ animal fat. Journal of the Science of Food and Agriculture 84, 1443-1450.
Edrington TS, Callaway TR, Anderson RC, Genovese KJ, Jung YS, McReynolds JL, Bischoff KM \& Nisbet DJ (2003) Reduction of E. coli $\mathrm{O} 157: \mathrm{H} 7$ populations in sheep by supplementation of an experimental sodium chlorate product. Small Ruminant Research 49, 173-181.

Eklund T (1985) The effect of sorbic acid and esters of p-hydroxybenzoic acid on the protonmotive force in Escherichia coli membrane vesicles. Journal of General Microbiology 131, $73-76$.

Fenech M (2002) Micronutrient and genomic stability: a new paradigm for recommended dietary allowances (RDAs). Food and Chemical Toxicology 40, 1113-1117.

Fenech M (2003) Nutritional treatment of genome instability: a paradigm shift in disease prevention and in the setting of recommended dietary allowances. Nutrition Research Reviews 16, 109-122.

Fernandez F, Sharma R, Hinton M \& Bedford MR (2000) Diet influences the colonisation of Campylobacter jejuni and the distribution of mucin carbohydrates in the chick intestinal tract. Cellular and Molecular Life Sciences 57, 1793-1801.

Geng AL, Guo YM \& Yang Y (2004) Reduction of ascites mortality in broilers by coenzyme $\mathrm{Q}_{10}$. Poultry Science 83, $1587-1593$

Gillies PJ (2003) Nutrigenomics: the Rubicon of molecular nutrition. Journal of the American Dietetic Association 103, Suppl. 2, S50-S55.

Hampson DJ, Phillips ND \& Pluske JR (2002) Dietary enzyme and zinc bacitracin reduce colonisation of layer hens by the intestinal spirochaete Brachyspira intermedia. Veterinary Microbiology 86, 351-360.

Hayek MG, Taylor SF, Bender BS, Han SN, Meydani M, Smith DE, Eghtesada S \& Meydani SN (1997) Vitamin E supplementation decreases lung virus titers in mice infected with influenza. Journal of Infectious Diseases 176, 273-276.

Hennet T, Peterhans E \& Stocker R (1992) Alterations in antioxidant defences in lungs and liver of mice infected with influenza A virus. Journal of General Virology 73, 39-46.

Holmberg T, Kaspersson A, Larsson K \& Pettersson H (1989) Aflatoxin production in moist barley treated with suboptimal doses of formic and propionic acid. Acta Agriculturae Scandinavica 39, 457-464.

Iqbal M, Cawthon D, Wideman RF Jr \& Bottje WG (2001) Lung mitochondrial dysfunction in pulmonary hypertension syndrome. II. Oxidative stress and inability to improve function with repeated additions of adenosine diphosphate. Poultry Science 80, 656-665.

Kim HW, Chew BP, Wong TS, Park JS, Weng BBC, Byrne KM, Hayek MG \& Reinhart GA (2000a) Modulation of humoral and cell-mediated immune responses by dietary lutein in cats. Veterinary Immunology and Immunopathology $\mathbf{7 3}$, $331-341$.

Kim HW, Chew BP, Wong TS, Park JS, Weng BBC, Byrne KM, Hayek MG \& Reinhart GA (2000b) Dietary lutein stimulates immune response in the canine. Veterinary Immunology and Immunopathology 74, 315-327.

Kong Q, Richter L, Yang YF, Arntzen CJ, Mason HS \& Thanavala Y (2001) Oral immunization with hepatitis B surface antigen expressed in transgenic plants. Proceedings of the National Academy of Science 98, 11539-11544.

Lavander OA (1997) Nutrition and newly emerging viral diseases: an overview. Journal of Nutrition 127, S948-S950.

Lee C-F, Han C-K \& Tsau J-L (2004) In vitro inhibitory activity of chinese leek extract against Campylobacter species. International Journal of Food Microbiology 94, 169-174.

Li YC, Ledoux DR, Bermudez AJ, Fritsche KL \& Rottinghaus GE (2000a) Effects of moniliformin on performance and immune function of broiler chicks. Poultry Science 79, 26-32. 
Li YC, Ledoux DR, Bermudez AJ, Fritsche KL \& Rottinghaus GE $(2000 b)$ The individual and combined effects of fumonisin $\mathrm{B}_{1}$ and moniliformin on performance and selected immune parameters in turkey poults. Poultry Science 79, 871-878.

Lindecrona RH, Jensen TK, Jensen BB, Leser TD, Jiufeng W \& Møller K (2003) The influence of diet on the development of swine dysentry upon experimental infection. Animal Science 76, $81-87$.

Lowry VK, Farnell MB, Ferro PJ, Swaggerty CL, Bahl A \& Kogut MH (2005) Purified $\beta$-glucan as an abiotic feed additive up-regulates the innate immune response in immature chickens against Salmonella enterica serovar Enteritidis. International Journal of Food Microbiology 98, 309-318.

McDonald DE, Pethick DW, Pluske JR \& Hampson DJ (1999) Adverse effects of soluble non-starch polysaccharide (guar gum) on piglet growth and experimental colibacillosis immediately after weaning. Research in Veterinary Science 67, 245-250.

Mead GC (2002) Factors affecting intestinal colonisation of poultry by campylobacter and role of microflora in control. World's Poultry Science Journal 58, 169-178.

Mills A \& Phillips CA (2003) Campylobacter jejuni and the human food chain: a possible source. Nutrition and Food Science 33, 197-202.

Miyamoto S, Kuwata G, Imai M, Nagao A \& Terao J (2000) Protective effect of phytic acid hydrolysis products on ironinduced lipid peroxidation of liposomal membranes. Lipids $\mathbf{3 5}$, 1411-1413.

Monroe DH, Holeski CJ \& Eaton DL (1986) Effects of single-dose and repeated-dose pre-treatment with 2(3)-tert-butyl-4-hydroxyanisole (BHA) on the hepatobiliary disposition and covalent binding to DNA of aflatoxin $\mathrm{B}_{1}$ in the rat. Food and Chemical Toxicology 24, 1273-1281.

Montagne L, Cavaney FS, Hampson DJ, Lallès JP \& Pluske JR (2004) Effect of diet composition on postweaning colibacillosis in piglets. Journal of Animal Science 82, 2364-2374.

Murota K, Mitsukuni Y, Ichikawa M, Tsushida T, Miyamoto S \& Terao J (2004) Quercetin-4'-glucoside is more potent than quecetin-3-glucoside in protection of rat intestinal mucosa homogenates against iron-induced lipid peroxidation. Journal of Agricultural and Food Chemistry 52, 1907-1912.

Park SF (2002) The physiology of Campylobacter species and its relevance to their role as foodborne pathogens. International Journal of Food Microbiology 74, 177-188.

Partanen KH \& Mroz Z (1999) Organic acids for performance enhancement in pig diets. Nutrition Research Reviews 12, $117-145$.

Peterhans E (1997) Oxidants and antioxidants in viral diseases: disease mechanisms and metabolic regulation. Journal of Nutrition 127, S962-S965.

Peterhans E, Grob M, Bürge T \& Zanoni R (1987) Virus-induced formation of reactive oxygen intermediates in phagocytic cells. Free Radical Research Communications 3, 39-46.

Pluske JR, Pethick DW, Hopwood DE \& Hampson DJ (2002) Nutritional influences on some major enteric bacterial diseases of pigs. Nutrition Research Reviews 15, 333-371.

Pluske JR, Siba PM, Pethick DW, Durmic Z, Mullan BP \& Hampson DJ (1996) The incidence of swine-dysentery in pigs can be reduced by feeding diets that limit the amount of fermentable substrate entering the large intestine. Journal of Nutrition 126, 2920-2933.

Ramos AJ \& Hernandéz E (1997) Prevention of aflatoxicosis in farm animals by means of hydrated sodium calcium aluminosilicate addition to feedstuffs: a review. Animal Feed Science and Technology 65, 197-206.

Risley CR, Kornegay ET, Lindemann MD \& Weakland SM (1991) Effects of organic acids with or without a microbial culture on performance and gastrointestinal tract measurements of weanling pigs. Animal Feed Science and Technology 35, 259-270.

Rizzo RF, Atroshi F, Ahotupa M, Sankari S \& Elovaara E (1994) Protective effect of antioxidants against free radical-mediated lipid peroxidation induced by DON or T-2 toxin. Journal of Veterinary Medicine 41A, 81-90.

Roy RD, Edens FW, Parkhurst CR, Quresh MA \& Havenstein GB (2002) Influence of a propionic acid feed additive on performance of turkey poults with experimentally induced poult enteritis and mortality syndrome. Poultry Science 81, 951-957.

Schell TC, Lindemann MD, Kornegay ET, Blodgett DJ \& Doerr JA (1993) Effectiveness of different types of clay for reducing the detrimental effects of aflatoxin-contaminated diets on performance and serum profiles of weanling pigs. Journal of Animal Science 71, 1226-1231.

Schwarzer K \& Adams CA (1996) The influence of specific phospholipids as absorption enhancer in animal nutrition. Fett Wissenschaft Technologie 98, 304-308.

Shanker S, Lee A \& Sorrel TC (1990) Horizontal transmission of Campylobacter jejuni amongst broiler chicks: experimental studies. Epidemiology and Infection 104, 101-110.

Surai PF, Noble RC \& Speake BK (1996) Tissue-specific differences in antioxidant distribution and susceptibility to lipid peroxidation during development of the chick embryo. Biochimica et Biophysica Acta 1304, 1-10.

Tacket CO, Mason HS, Losonsky G, Estes ME, Levine MM \& Arntzen CJ (2000) Human immune responses to a novel norwalk virus vaccine delivered in transgenic potatoes. Journal of Infectious Diseases 182, 302-305.

Udayamputhoor RS, Hariharan H, van Lunen TA, Lewis PJ, Heaney S, Price L \& Woodward D (2003) Effects of diet formulations containing proteins from different sources on intestinal colonization by Campylobacter jejuni in broiler chickens. Canadian Journal of Veterinary Research 67, 204-212.

Valdivia AG, Martinez A, Damián FJ, Quezada T, Ortiz R, Martinez C, Llamas J, Rodriguez ML, Yamamoto L, Jaramillo F, Loarca-Pina MG \& Reyes JL (2001) Efficacy of $\mathrm{N}$-acetylcysteine to reduce the effects of aflatoxin B1 intoxication in broiler chickens. Poultry Science 80, 727-743.

van Immerseel F, De Buck J, Pasmans F, Huyghebaer G, Hasebrouck F \& Ducatelle R (2004) Clostridium perfringens in poultry: an emerging threat to animal and public health. Avian Pathology 33, 537-549.

van Vliet AHM, Ketley JM, Park SF \& Penn CW (2002) The role of iron in Campylobacter gene regulation, metabolism and oxidative stress. FEMS Microbiology Reviews 26, $173-186$.

Wiseman H (1999) The bioavailability of non-nutrient plant factors: dietary flavonoids and phyto-oestrogens. Proceedings of the Nutrition Society 58, 139-146.

Wright AC, Simpson LM \& Oliver JD (1981) Role of iron in the pathogenesis of Vibrio vulnificus infections. Infection and Immunology 43, 503-507.

Wu G, Meier SA \& Knabe DA (1996) Dietary glutamine supplementation prevents atrophy in weaned piglets. Journal of Nutrition 126, 2578-2584.

Xing JJ, van Heugten E, Li DF, Touchette KJ, Coalson JA, Odgaard RL \& Odle J (2004) Effects of emulsification, fat encapsulation, and pelleting on weanling pig performance and nutrient digestibiblity. Journal of Animal Science 82, $2601-2609$

Yu J \& Langrióge HR (2001) A plant-based multicomponent vaccine protects mice from enteric diseases. Nature Biotechnology 19, $548-552$. 